\title{
Structure and properties of masonry mortars based on ceramic microspheres
}

\author{
Vyacheslav Semenov* \\ Moscow State University of Civil Engineering, Yaroslavskoe shosse, 26, Moscow, 129337, Russia
}

\begin{abstract}
Modern requirements in the field of energy and resource saving determines the need to apply effective fencing structures. To ensure the thermal homogeneity of the structures erected with small-piece masonry elements (ceramic and light-weight concrete units etc.), it is necessary to use lightweight mortars. One of the most effective methods to obtain such mortars is the introduction of hollow ceramic microspheres as a filler into their composition. The purpose of this work is studying of the composition and structure of a cement masonry mortar with hollow ceramic microspheres and modifying additives in correlation with its properties. The methods of thermogravimetric analysis, scanning electron microscopy, $\mathrm{X}$-ray diffraction and standard test methods for the masonry mortars were used. The effect of the structural characteristics of the composite on the properties of final product was analyzed. It is established that the microstructure of the modified mortar samples is more compact in compare with basic composition, and the surface of the microspheres is covered by the products of the chemical interaction of its walls with the cement matrix. The aforesaid research allowed to obtain the high-performance lightweight mortars with hollow ceramic microspheres.
\end{abstract}

\section{Introduction}

Nowadays, the problems of developing efficient materials for the construction of low-cost housing, import substitution, expanding the range of domestic building materials are the priorities for the development of the construction industry in the Russian Federation. Modern requirements in the field of energy and resource saving determine the need for effective fencing of buildings [1], for the erection of which piece wall products (lightweight concrete blocks, ceramic elements, etc.) are often used. To ensure the thermal homogeneity of such enclosing structures, lightweight masonry mortars are used [2]. The complexity of lightweight mortars determines mainly the use of dry mixes for their production. Such mortars (dry mixes) are expensive, in some cases they have only minimal physical-andmechanical and performance properties [3]. The average density of the masonry mortar should be close to the average density of the wall material, and the compressive strength should be by $20 \ldots 25 \%$ higher than the strength of the wall material, which is a condition for ensuring the design strength of the building fencing. The frost resistance of the mortar,

\footnotetext{
* Corresponding author: science-isa@yandex.ru
} 
which is a parameter of the durability of the structure, should not be lower than the frost resistance of the wall material. Traditionally, such lightweight masonry mixtures are obtained by introducing lightweight aggregates into their composition - expanded perlite or vermiculite sands, foam glass or expanded polystyrene granules, etc. [3-4].

Cement compositions using hollow microspheres (glass, ceramic (aluminosilicate), polymeric) as a lightweight aggregate are being more and more studied and developed [59]. The spherical shape of the aggregate provides a greater plasticity of mixtures and a higher compressive strength. The introduction of hollow microspheres as a filler into the composition of dry masonry mixtures makes it possible to obtain an effective composite material with high strength and thermal properties [10-13]. One of the most effective methods of obtaining such mortars is the introduction of hollow ceramic microspheres and a complex of modifying additives into their composition [14]. Note that the ceramic microspheres are, in fact, industrial waste product [3]. Therefore, the further development of this subject-matter is relevant and allows to achieve the indicators of the Strategy for the development of the construction materials industry in the Russian Federation until 2030 improving energy efficiency and availability of low-cost building materials, using waste products as raw materials.

It is known that the properties of a material are determined by its composition and structure. Therefore, a qualitative and scientifically based result can be obtained only with an integrated approach, involving the study of both the composition and the structure of the material obtained, which was the purpose of this work.

\section{Materials and methods}

To obtain a lightweight masonry mortar the following materials were used. Portland cement CEM I $42.5 \mathrm{~N}$ was used as a binder. Hollow ceramic thin-walled microspheres (HCMS) with a fraction of $1 . . .500 \mu \mathrm{m}$ (INOTEK, Siberia Kuznetsky) were used as a lightweight aggregate. The average particle size was $300 \mu \mathrm{m}$, the microsphere wall thickness was equal to $0.1 \ldots 10 \mu \mathrm{m}$. The bulk density of the microspheres was $370 \ldots 390 \mathrm{~kg} / \mathrm{m}^{3}$, the strength under hydrostatic compression (10\% failure) was $15 \ldots .28 \mathrm{MPa}$, the thermal conductivity coefficient of the microspheres was $0.08 \mathrm{~W} /\left(\mathrm{m}^{\circ}{ }^{\circ} \mathrm{C}\right)$ at $20^{\circ} \mathrm{C}$. To reduce the water requirement of the mortar mixes, PERAMIN SMF 10 superplasticizer (melamine sulfonate) was used. As a modifier of the structure, an air-entraining additive (AEA) ASCO 93, which is an anionic surfactant based on a high molecular weight olefin sulfonate, and a redispersible polymer powder (RPP) Vinnapas 8034, were used.

Determination of the main properties of mortar mixes and masonry mortars was carried out according to standard methods (GOST). For a quantitative assessment of the composition of new growth in lightweight masonry mortar samples, the method of thermogravimetric analysis (TGA) was used on a SETARAM LABSYS TGA / DSC / DTA instrument. The registration of derivatograms was carried out within the temperature range from $50^{\circ} \mathrm{C}$ to $1000^{\circ} \mathrm{C}$ with a uniform heating rate of $10^{\circ} \mathrm{C} / \mathrm{min}$. All measurements were carried out in air. Microstructural analysis of lightweight masonry mortar samples was carried out using an FEI Quanta 200 scanning electron microscope. Phase analysis of lightweight masonry mortar samples was performed on an ARL X'tra diffractometer.

\section{Results and discussion}

Previously, the authors in [15] used computer simulation methods for the structure of cement mortar with hollow ceramic microspheres to calculate the optimal aggregate content of a given particle size distribution, which achieves the most dense particle packing $-60 \%$ 
of the binder mass. In this case, theoretically, the highest specific strength of the composite is achieved. The average density of the resulting mortar in the dry state was $950 \mathrm{~kg} / \mathrm{m}^{3}$ with the ultimate compressive strength of $17.1 \mathrm{MPa}$, and the bending strength of $2.8 \mathrm{MPa}$. Further, the obtained optimal composition of the mortar, containing $60 \%$ of HCMS of the binder mass and superplasticizer at a dosage of $0.4 \%$ of the binder mass, was modified with an air-entraining additive and a redispersible polymer powder.

The introduction of air-entraining additives improves the workability of the mortar mixture, increases the frost resistance of the mortar and reduces its average density. RPP improves the physical-and-mechanical and technological properties of the mortar. The results of this study were described in detail in [14], on the basis of which the optimal compositions of lightweight masonry mortar were determined. The compositions and properties of masonry mortars with HCMS, AEA and RPP are given in table. 1 and 2.

Table 1. Compositions and properties of light-weight masonry mortars with hollow ceramic microspheres, redispersible polymer powder and air-entraining additive

\begin{tabular}{|c|c|c|c|c|c|c|c|c|c|}
\hline \multirow{2}{*}{ No } & \multicolumn{4}{|c|}{ Composition, mass, \% } & \multirow{2}{*}{ W/C } & $\begin{array}{c}\text { Average density } \\
\text { of mortar in dry } \\
\text { state, } \mathrm{kg} / \mathrm{m}^{3}\end{array}$ & \multicolumn{2}{|c|}{$\begin{array}{c}\text { Strength at the age of } \\
\text { 28 days, MPa }\end{array}$} \\
\cline { 2 - 4 } & PC & HCMS & SP & AEA & V 8034 H & & & & \\
\hline 1 & 100 & 60 & 0,4 & - & - & 0,65 & 51 & 17,14 & 2,76 \\
\hline 2 & 100 & 60 & 0,4 & 0,02 & - & 0,71 & 576 & 5,01 & 1,67 \\
\hline 3 & 100 & 60 & 0,4 & 0,02 & 3 & 0,76 & 598 & 8,38 & 1,89 \\
\hline
\end{tabular}

Notes: PC - Portland cement; HCMS - hollow ceramic microspheres; SP - superplasticizer; AEA air-entraining additive; V $8034 \mathrm{H}$ - redispersible polymer powder Vinnapas $8034 \mathrm{H}$.

Table 2. Main exploitation properties of light-weight masonry mortars with hollow ceramic microspheres, redispersible polymer powder and air-entraining additive

\begin{tabular}{|c|c|c|c|c|c|c|}
\hline \multirow{2}{*}{ No } & $\begin{array}{c}\text { Average } \\
\text { density of } \\
\text { mortar in dry } \\
\text { state, } \mathrm{kg} / \mathrm{m}^{3}\end{array}$ & $\begin{array}{c}\text { Coefficient of } \\
\text { thermal conductivity } \\
\text { of the mortar in dry } \\
\text { state, } \mathrm{W} /\left(\mathrm{m}^{\circ}{ }^{\circ} \mathrm{C}\right)\end{array}$ & \multicolumn{2}{|c|}{$\begin{array}{c}\text { Water absorption, } \\
\%\end{array}$} & \multirow{2}{*}{$\begin{array}{c}\text { Water absorption at } \\
\text { capillary suction, } \\
\mathrm{kg} /\left(\mathrm{m}^{2} \cdot \text { hours }^{0,5}\right)\end{array}$} & $\begin{array}{c}\text { Freeze- } \\
\text { thaw } \\
\text { durability, } \\
\text { cycles }\end{array}$ \\
\hline 1 & 951 & 0,244 & 8,1 & 8,1 & 0,3 & 100 \\
\hline 2 & 576 & 0,146 & 13,9 & 13,9 & 0,4 & 50 \\
\hline 3 & 598 & 0,152 & 9,2 & 9,2 & 0,2 & 75 \\
\hline
\end{tabular}

The structure and chemical composition of the samples of the mortar of the control and modified compositions were investigated by scanning electron microscopy. Fig. 1 shows the microstructure of a lightweight masonry mortar with hollow ceramic microspheres.
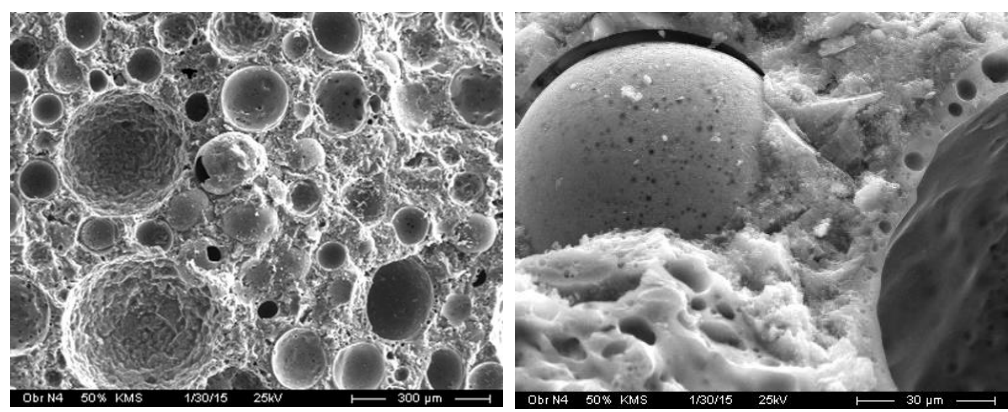

Fig. 1. Microstructure of lightweight masonry mortar with hollow ceramic microspheres

It is represented mainly by uniformly distributed in volume hollow ceramic microspheres and a dense cement matrix of amorphous low-base calcium hydrosilicates (C$\mathrm{S}-\mathrm{H}(\mathrm{I})$ ). Portlandite is present in minor quantities. The destruction occurs mainly in the 
microspheres, in some cases - in the contact zone "ceramic microsphere - cement matrix". This indicates the high strength of the cement matrix. The presence of a large volume of capillary pores is noted, and spherical air pores are also present.

Fig. 2 shows the microstructure of a lightweight masonry mortar with hollow aluminosilicate microspheres, air-entraining additive and redispersible polymer powder.
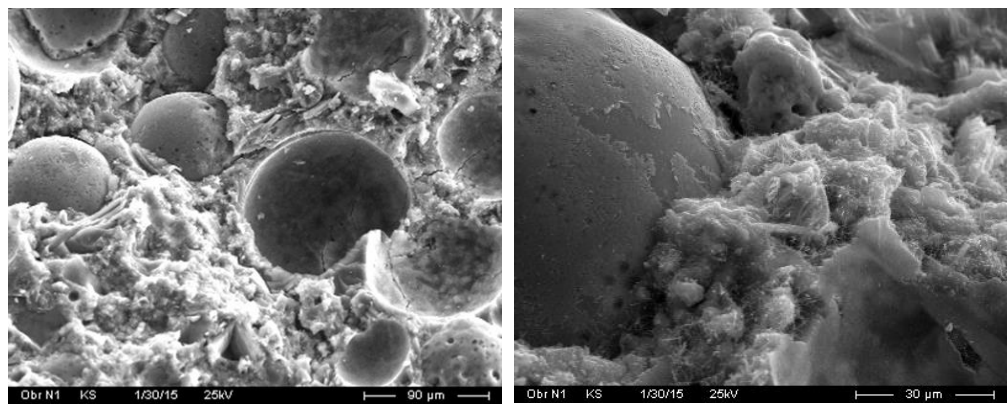

Fig. 2. Microstructure of lightweight masonry mortar with hollow ceramic microspheres, redispersible polymer powder and air-entraining additive

The microstructure of the sample is also represented by microspheres uniformly distributed throughout the cement stone and looser than the unmodified composition of the cement matrix, due to the presence of an air-entraining additive in its composition, which reduces the average density of the solution with the same content of microspheres. The cement matrix consists mainly of strong, weakly crystallized, highly basic calcium hydrosilicates with the ratio $\mathrm{CaO} / \mathrm{SiO}_{2}=1.88$ (C-S-H (II)) with inclusions of crystallized low-strength needle-like calcium hydrosilicates. The presence of portlandite crystals is also noted. The destruction occurs mainly in the contact zone "ceramic microsphere - cement matrix" and the cement matrix. It is noted that the surface of microspheres is covered with a layer of new growths with a thickness of not more than $1 \mu \mathrm{m}$, which indicates the physicaland-chemical interaction of highly basic calcium hydrosilicates with a ceramic microsphere. Analysis of photographs of the microstructure of masonry mortar samples with HCMS, AEA and RPP indicates a decrease in the volume of the large capillary pores of the cement matrix compared with the unmodified composition.

Details of the contact zone "ceramic microsphere - cement matrix" are shown in Fig. 3. Chemical analysis of these sites is given in table. 3

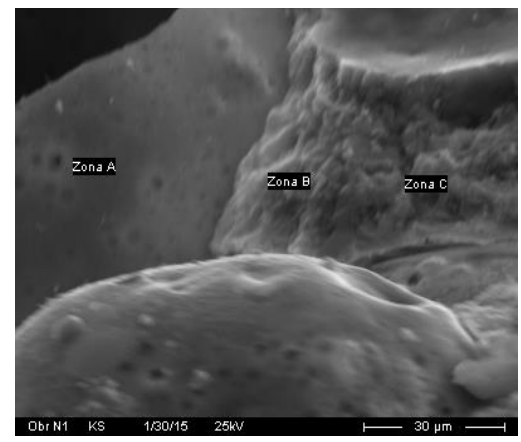

Fig. 3. Area of the contact zone "hollow ceramic microsphere - cement matrix"

In zone A, an analysis was made of the wall of a hollow ceramic microsphere. Compared with the results of chemical analysis of microspheres, the content of $\mathrm{SiO}_{2}$ and $\mathrm{CaO}$ increased, the content of $\mathrm{Al}_{2} \mathrm{O}_{3}$ and $\mathrm{Fe}_{2} \mathrm{O}_{3}$ decreased, which may also indicate the chemical interaction between the microspheres and the products of Portland cement 
hydration. Section B represents the contact zone of the microsphere and the cement matrix, and section $\mathrm{C}$ represents the cement matrix, which consist of weakly crystallized highly basic calcium hydrosilicates with a dense structure, hydroaluminates and calcium hydroferrites.

Table 3. Chemical analysis of the areas of the "hollow ceramic microsphere - cement matrix" contact zone

\begin{tabular}{|c||c|c|c|c|}
\hline \multicolumn{1}{|c||}{ Oxide } & \multicolumn{4}{c|}{ Content, mass. \% } \\
\cline { 2 - 5 } & Zone A & Zone B & Zone C & Microsphere \\
\hline \hline $\mathrm{SiO}_{2}$ & 54,64 & 23,21 & 25,81 & 52,79 \\
\hline $\mathrm{CaO}$ & 6,53 & 46,79 & 47,12 & 3,37 \\
\hline $\mathrm{Al}_{2} \mathrm{O}_{3}$ & 27,82 & 12,11 & 10,02 & 30,92 \\
\hline $\mathrm{Fe}_{2} \mathrm{O}_{3}$ & 3,61 & 11,43 & 10,78 & 4,96 \\
\hline $\mathrm{MgO}$ & 2,45 & 2,24 & 2,11 & 3,16 \\
\hline $\mathrm{K}_{2} \mathrm{O}$ & 3,59 & 0,49 & 0,47 & 3,07 \\
\hline $\mathrm{TiO}_{2}$ & 1,35 & - & - & 2,33 \\
\hline $\mathrm{SO}$ & - & 2,79 & 3,21 & - \\
\hline
\end{tabular}

Fig. 4 shows an X-ray diagram of a lightweight masonry mortar sample with hollow ceramic microspheres.

The X-ray diagram shows the following compounds: alite - $\mathrm{C}_{3} \mathrm{~S}$ $\left(54 \mathrm{CaO} \cdot 16 \mathrm{SiO}_{2} \cdot \mathrm{Al}_{2} \mathrm{O}_{3} \cdot \mathrm{MgO}\right)$; tricalcium aluminate $\mathrm{C}_{3} \mathrm{~A}\left(3 \mathrm{CaO} \cdot \mathrm{Al}_{2} \mathrm{O}_{3}\right)$; belite $-\beta_{\mathrm{L}}-\mathrm{C}_{2} \mathrm{~S}$ (larnite); tetracalcium alumoferrite $\mathrm{C}_{4} \mathrm{AF}$ (brownmillerite); portlandite $-\mathrm{Ca}(\mathrm{OH})_{2} ; \mathrm{CSH}(\mathrm{I}$ ) - CSH(B) - partially crystallized tobermoric calcium hydrosilicate; $\mathrm{CSH}(\mathrm{II})$; calcite $\mathrm{CaCO}_{3}$; calcium hydrosilicate $3 \mathrm{CaO} \cdot 2 \mathrm{SiO}_{2} \cdot 3 \mathrm{H}_{2} \mathrm{O}$; calcium hydroaluminate $3 \mathrm{CaO} \cdot \mathrm{Al}_{2} \mathrm{O}_{3} \cdot 6 \mathrm{H}_{2} \mathrm{O}$; ettringite $3 \mathrm{CaO} \cdot \mathrm{Al}_{2} \mathrm{O}_{3} \cdot 3 \mathrm{CaSO}_{4} \cdot 32 \mathrm{H}_{2} \mathrm{O}$, calcium hydroferrite $3 \mathrm{CaO} \cdot \mathrm{Fe}_{2} \mathrm{O}_{3} \cdot 6 \mathrm{H}_{2} \mathrm{O}$.

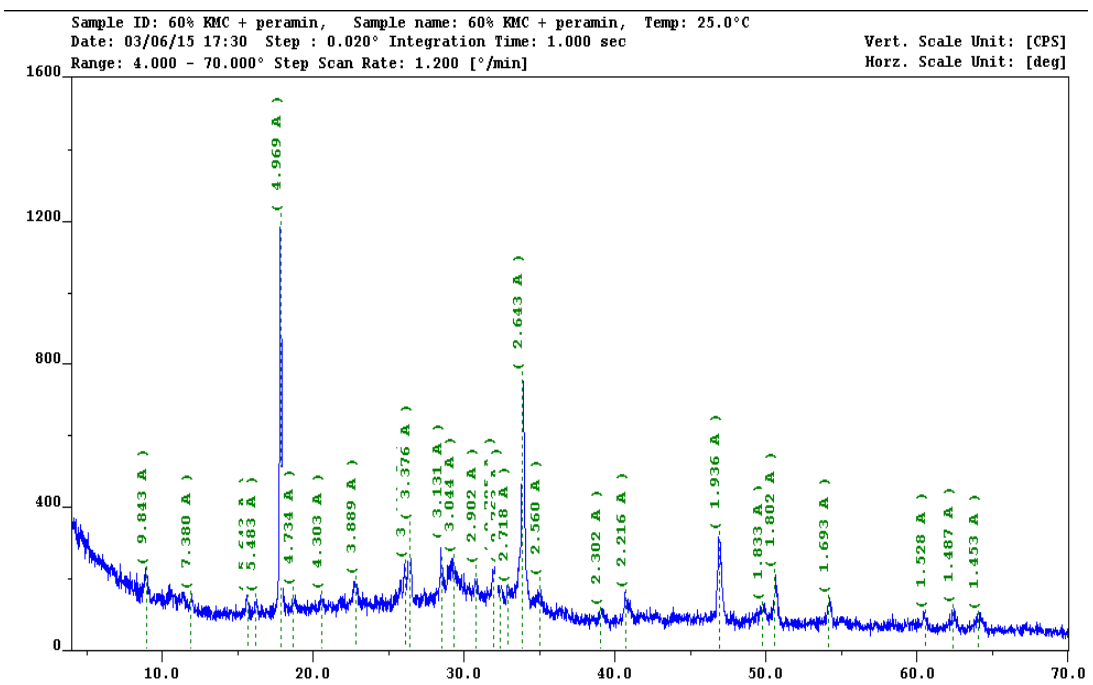

Fig. 4. X-ray diagram of lightweight masonry mortar with hollow ceramic microspheres

In fig. 5 shows an X-ray diagram of a lightweight masonry mortar with hollow ceramic microspheres, an air-entraining additive and a redispersible polymer powder. In the composition of lightweight masonry mortar samples with HCMS, AEA and RPP, after identification, the compounds similar to those found on the X-ray diagram of the unmodified composition are detected. On the X-ray diagram of a modified composition 
sample a significant increase in the intensity of the peaks of portlandite and calcium hydrosilicates (CSH (II)) was observed, which indicates an increase in the degree of their crystallinity compared with the unmodified composition.

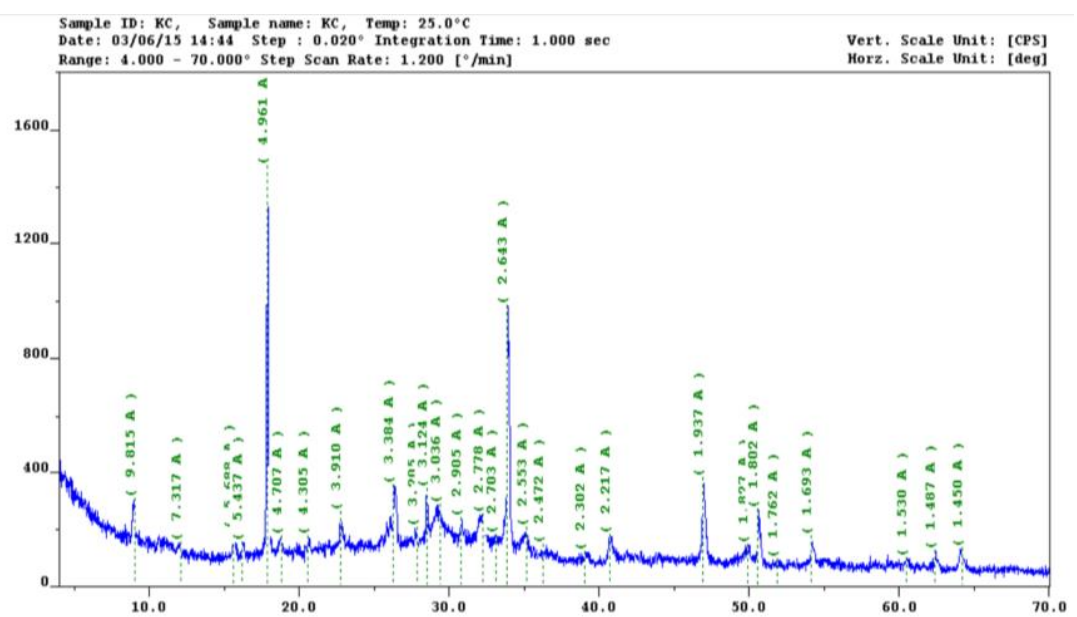

Fig. 5. X-ray diagram of lightweight masonry mortar with hollow ceramic microspheres, redispersible polymer powder and air-entraining additive

The hydration degree of a lightweight mortar with HCMS, AEA and RPP is equal to $74.1 \%$ and the hydration degree of unmodified composition is equal to $66.5 \%$.

To quantify the composition of new growths, a thermogravimetric analysis of lightweight masonry mortar samples was also performed. Fig. 6 shows a derivatogram of a lightweight masonry mortar with hollow ceramic microspheres and Fig. 7 presents a derivatogram of a lightweight masonry mortar with a CCM, VVD and RPP.

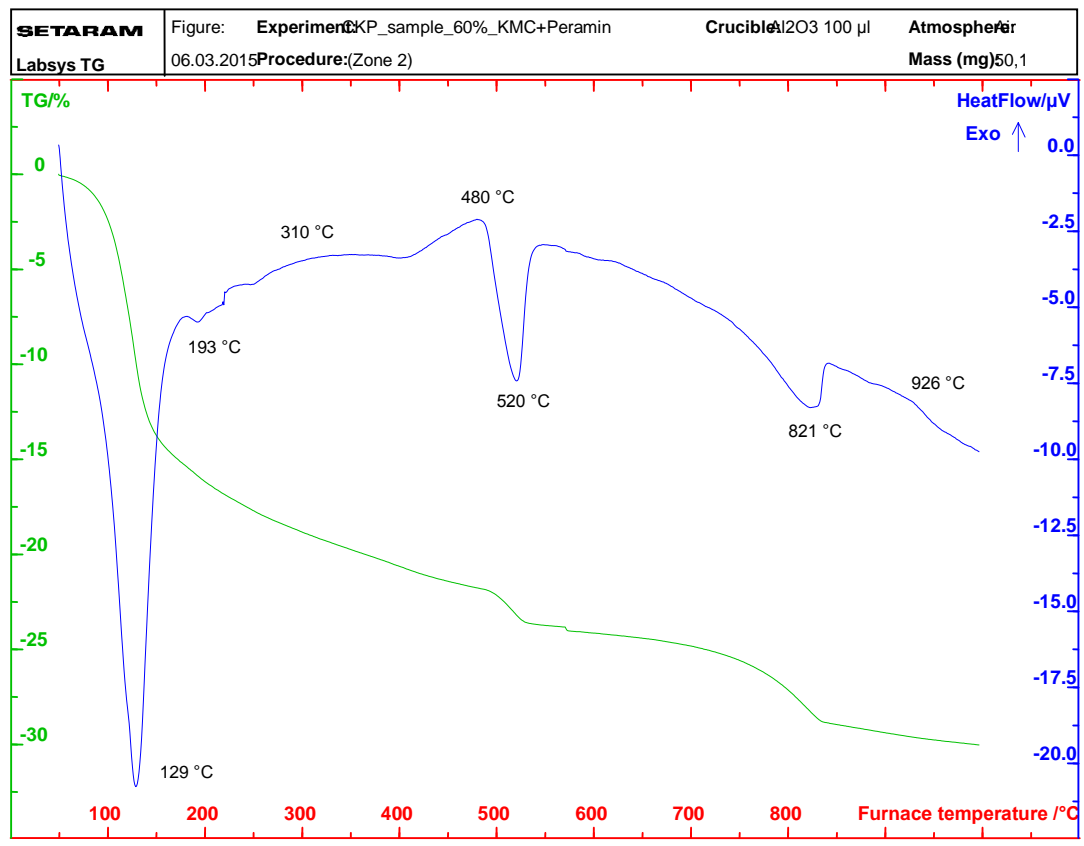

Fig. 6. Derivatogram of lightweight masonry mortar with hollow ceramic microspheres 
It should be noted three endothermic effects typical for cement systems, caused by the removal of free water and crystal hydrate water from calcium hydrosulphoaluminate $\left(129^{\circ} \mathrm{C}\right.$ and $\left.130^{\circ} \mathrm{C}\right)$, dehydration of $\mathrm{Ca}(\mathrm{OH})_{2}\left(520^{\circ} \mathrm{C}\right.$ and $\left.517^{\circ} \mathrm{C}\right)$ and dissociation of $\mathrm{CaCO}_{3}$ $\left(821^{\circ} \mathrm{C}\right.$ and $\left.822^{\circ} \mathrm{C}\right)$.

For the unmodified composition, the mass loss in the first effect when removing free water is $15 \%$, the mass loss in the second effect when decomposing $\mathrm{Ca}(\mathrm{OH})_{2}$ is $1.94 \%$, the content of $\mathrm{Ca}(\mathrm{OH})_{2}$ is $7.98 \%$. The mass loss in the third effect in the dissociation of $\mathrm{CaCO}_{3}$ is $3.77 \%$, the content of $\mathrm{CaCO}_{3}$ is $8.57 \%$. The total mass loss is $30 \%$ of the initial mass, which corresponds to the water loss.

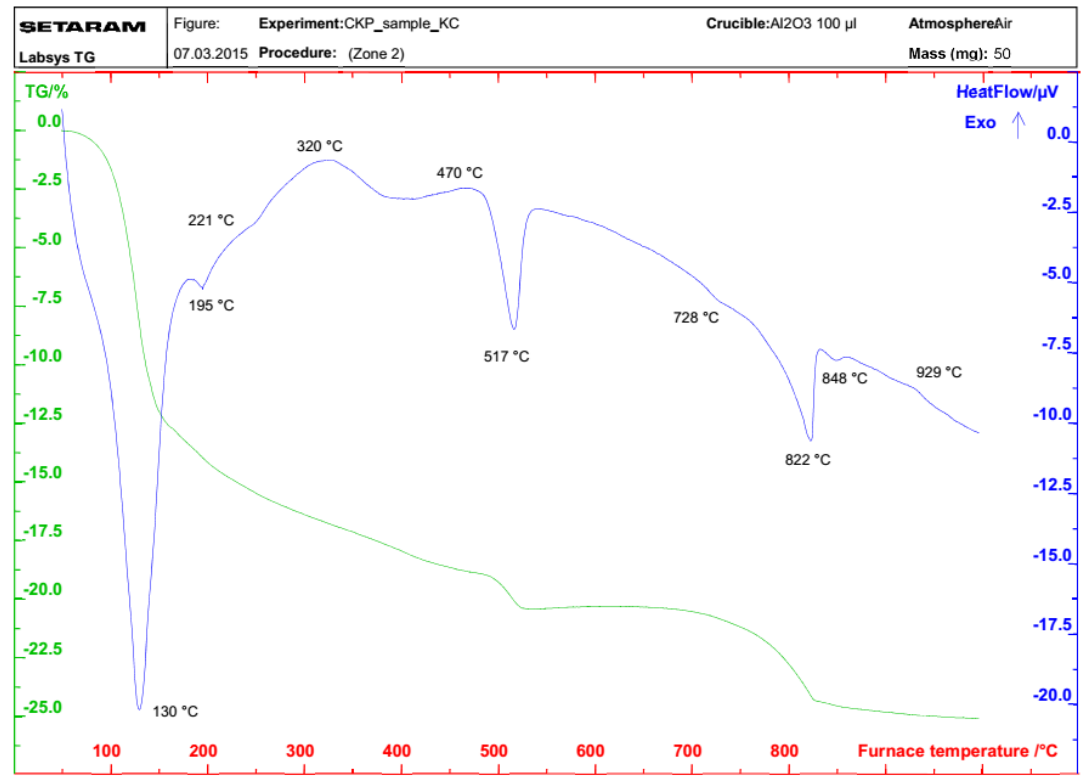

Fig. 7. Derivatogram of lightweight masonry mortar with hollow ceramic microspheres, redispersible polymer powder and air-entraining additive

For the modified composition, the mass loss in the first effect when removing free water is $13.4 \%$, the mass loss in the second effect when decomposing $\mathrm{Ca}(\mathrm{OH})_{2}$ is $1.47 \%$, the content of $\mathrm{Ca}(\mathrm{OH})_{2}$ is $6.04 \%$. The mass loss in the third effect in the dissociation of $\mathrm{CaCO}_{3}$ is $3.16 \%$, the content of $\mathrm{CaCO}_{3}$ is $7.18 \%$. The total weight loss is $25 \%$ of the initial mass.

\section{Conclusions}

As a result of the research work, it was established that the modification of the lightweight masonry mortar based on hollow ceramic microsphere with the complex of plasticizer, airentraining additives and redispersible polymer powder allowed to obtain the highperformance lightweight mortars with an average density in the dry state of 500...1000 $\mathrm{kg} / \mathrm{m}^{3}$, strength values of 5.0..17.0 MPa, freeze-thaw durability of $50 \ldots 100$ cycles and coefficient of thermal conductivity in the dry state of $0.146 \ldots 0.245 \mathrm{~W} /(\mathrm{m} \cdot \mathrm{K})$. It has been established that the microstructure of modified masonry mortar is represented by microspheres and a cement matrix uniformly distributed throughout the cement stone from durable, partially crystallized, highly basic calcium hydrosilicates with a ratio of $\mathrm{CaO} / \mathrm{SiO}_{2}=1.88$ (C-S-H (II)) with inclusions of crystallized low-strength needle hydrosilicates. The surface of the microspheres is covered with products of chemical interaction of their walls with the cement matrix, which leads to an increase in the strength 
of the contact zone "ceramic microsphere - cement matrix", this is also indicated by a decrease in the content in the modified composition of portlandite by $24 \%$ compared with the composition without functional additives according to the results of thermogravimetric analysis. The degree of crystallization of calcium hydrosilicates (CSH (II)) for a lightweight masonry mortar with HCMS, AEA and RPP is higher than for unmodified composition. It is shown that high performance characteristics of the mortars were obtained by a purposeful modification of the composition and structure of the cement composite with ceramic microspheres.

This work was financially supported by Ministry of Science and Higher Education of the Russian Federation (\#NSh-3492.2018.8).

\section{References}

1. V. Gagarin, V. Kozlov, Vestnik MGSU, 3(1), 192 (2011)

2. D. Oreshkin, V. Semenov, T. Rozovskaya, Pr. Eng., 153, 638 (2016)

3. V. Semenov, T. Rozovskaya, IOP Conf. Ser.: Mat. Sc. and Eng., 71(1), 012042 (2015)

4. R. Demirboğa, İ. Örüng, R Gül, Cem. and Concr. Res., 31 (11), 1627 (2001)

5. Z. Li, Z. Su, L. Li, H. Mi, W. Meng, Y. Huang, J. Yang, J. of the Ch. Cer. Soc., 45(3), 384 (2017).

A. Inozemtcev, E. Korolev, Key Eng. Mat., 743, 68 (2017)

6. Bessonov, O. Larsen, L. Alimov, V. Voronin, A. Sapelin, N. Komorova, IOP Conf. Ser.: Mat. Sc. and Eng., 365(3), 032011 (2018)

7. Z. Huang, F. Wang, Y. Zhou, L. Sui, P. Krishnan, J.Y.R. Liew, Mat., 11(10), 2043 (2018)

8. Z. Huang, K. Padmaja, S. Li, J.Y.R. Liew, Constr. and Build. Mat., 164, 760 (2018)

9. A. Inozemtcev, E. Korolev, V. Smirnov, Struct. Concr., 18(1), 67 (2017)

10. P. Chen, J. Wang, F. Liu, X. Qian, Y. Xu, J. Li, Constr. and Build. Mat., 159, 431 (2018)

11. A. Brooks, H. Zhou, D. Hanna, Constr. and Build. Mat., 159, 316 (2018)

12. V. Rheinheimer, Y. Wu, T. Wu, K. Celik, J. Wang, L. De Lorenzis, P. Wriggers, M.-H. Zhang, P.J.M. Monteiro, Cem. and Concr. Comp., 80, 91 (2017)

13. A. Hanif, Z. Lu, S. Diao, X. Zeng, Z. Li, Constr. and Build. Mat., 140, 139 (2017)

14. V. Semenov, MATEC Web of Conf., 117, 00149 (2017)

15. V. Smirnov, T. Rozovskaya, V. Semenov, Sc. Rev., 10-2, 78 (2015) 